\title{
INTRODUCING MEDICAL PARASITOLOGY AT THE UNIVERSITY OF MAKENI, SIERRA LEONE
}

\author{
A. Peña-Fernández', U. Anjum², S. Koroma ${ }^{3}$, R.E. Guetiya Wadoum ${ }^{3}$, \\ F. Izquierdo ${ }^{4}$, A. Magnet ${ }^{4}$, L. Acosta ${ }^{5}$, M. Berghs ${ }^{1}$, M.C. Lobo-Bedmar ${ }^{6}$ \\ ${ }^{1}$ De Montfort University, Leicester School of Allied Health Sciences (UNITED KINGDOM) \\ ${ }^{2}$ Leicester School of Allied Health Sciences, De Montfort University (UNITED KINGDOM) \\ ${ }^{3}$ University of Makeni, Department of Public Health (SIERRA LEONE) \\ ${ }^{4}$ Universidad San Pablo CEU, Facultad de Farmacia (SPAIN) \\ ${ }^{5}$ Universidad Miguel Hernández de Elche, Department of Parasitology (SPAIN) \\ 6IMIDRA, Departamento de Investigación Agroambiental (SPAIN)
}

\begin{abstract}
Capacity building in Sierra Leone (West Africa) is critical to prevent potential future outbreaks similar to the 2013-16 Ebola outbreak that had devastating effects for the country and its poorly developed healthcare system. De Montfort University (DMU) in the United Kingdom (UK), in collaboration with parasitologists from the Spanish Universities of San Pablo CEU and Miguel Hernández de Elche, is leading a project to build the teaching and research capabilities of medical parasitology at the University of Makeni (UniMak, Sierra Leone). This project has two objectives: a) to introduce and enhance the teaching of medical parasitology, both theoretical and practical; and b) to implement and develop parasitology research related to important emerging human parasites such as Cryptosporidium spp. due to their public health significance. Two UniMak academics, hired to help initiate and implement the research part of the project, shared their culturally sensitive public health expertise to broker parasitology research in communities and perform a comprehensive environmental monitoring study for the detection of different emerging human parasites. The presence of targeted parasites are being studied microscopically using different staining techniques, which in turn have allowed UniMak's academics to learn these techniques to develop new practicals in parasitology. To train UniMak's academics and develop both parts of our project, a DMU researcher visited UniMak for two weeks in April 2019 and provided a voluntary short training course in basic parasitology, which is currently not taught in any of their programmes, and was attended by 31 students. These sessions covered basic introduction to medical parasitology and life-cycle, pathogenesis, detection, treatment and prevention of: a) coccidian parasites (Cryptosporidium, Cyclospora and Cystoisospora); b) Giardia intestinalis, Entamoeba and free-living amoebas; c) malaria and d) microsporidia. A theoretical session on common staining techniques was also provided. To facilitate the teaching and learning of these parasites, the novel resource DMU e-Parasitology was used, a package developed by the above participating universities and biomedical scientists from the UK National Health Service (NHS): http://parasitology.dmu.ac.uk/ index.htm. Following the two weeks of training, UniMak's academics performed different curriculum modifications to the undergraduate programme 'Public Health: Medical Laboratory Sciences', which includes the introduction of new practicals in parasitology and changes to enhance the content of medical parasitology that will be subjected to examination. Thus, a new voluntary practical on Kinyoun stain for the detection of coccidian parasites was introduced in the final year module of 'Medical Bacteriology and Parasitology'; eighteen students in pairs processed faecal samples from pigs provided by the Department of Agriculture and Food Security from a nearby farm. Academics at UniMak used the Kinyoun staining unit (available at http://parasitology.dmu.ac.uk/learn/lab/Kinyoun/story_html5.html; [1]) to deliver this practical. Although our project is at a preliminary stage, it has been shown to be effective in promoting the introduction and establishment of medical parasitology at UniMak and could be viewed as a case-study for other universities in low-income countries to promote the United Nations (UN) Sustainable Development Goals (SDGs) and improve public health understanding of infectious diseases.
\end{abstract}

Keywords: DMU e-Parasitology, staining techniques, University of Makeni, capabilities, medical parasitology. 


\section{INTRODUCTION}

A nationwide retrospective cohort study recently completed in Guinea (West Africa) has identified an increased risk of mortality in survivors from the devastating 2013-16 Ebola virus disease outbreak [2], individuals which will require specific countermeasures to protect their compromised health. Thus, identification of potential acute and opportunistic infections in West African countries will be crucial to identify appropriate preventive health or therapeutic interventions highlighted in light of new evidence of increased mortality in Ebola survivors [3].

Our parasitology research group at De Montfort University (DMU, UK), in collaboration with parasitologists from the Spanish Universities of San Pablo CEU (Madrid) and Miguel Hernandez de Elche (Alicante), and researchers from University of Makeni (UniMak, Sierra Leone), has undertaken a project to determine the presence and distribution of emerging opportunistic human pathogens in Sierra Leone. This un-known information is necessary to identify and tailor applicable and effective interventions to prevent infections and exposure in at-risk individuals, including Ebola survivors, HIV positive patients, and vulnerable populations, such as children and the elderly, which have not got fully developed and/or affected immune systems. We are focussing on Sierra Leone because this is the country with the highest number of documented Ebola survivors in West Africa, according to the latest Ebola Situation Report published by the World Health Organisation (WHO) after lifting the Public Health Emergency of International Concern (PHEIC) related to Ebola in West Africa on the 29th March 2016 [4].

Moreover, as part of this project, we are working on building the research and teaching capabilities in parasitology at UniMak, as in post-Ebola Sierra Leone, capacity building is critical to prevent future outbreaks. The main aim of this paper is to provide a description of our project, which was informed by good cultural and ethical practices, with a particular focus on different activities to implement and enhance the teaching of parasitology at UniMak.

\section{METHODOLOGY}

In order to meet the aims of this study, we have undertaken the following main two tasks or phases.

\subsection{Phase 1: introducing parasitology teaching.}

A DMU researcher visited UniMak for two weeks in April 2019 and provided a short training course, theoretical and practical, in basic parasitology (22 hours) to volunteer UniMak's undergraduate students. Basic parasitology is currently not taught in any undergraduate programmes, except for a few practical sessions in malaria in the degree 'Public Health: Medical Laboratory Sciences'. Teaching sessions covered a basic introduction to medical parasitology and important parasitic diseases and emerging opportunistic protozoan and fungi human parasites that could affect the Sierra Leonean population, as described in Table 1.

To facilitate the teaching and learning of these parasites, the novel resource DMU e-Parasitology ${ }^{\circledR}$ was used, a virtual package accessible from the DMU website (http://parasitology.dmu.ac.uk/index.htm; [5]). This resource has four sections, which will cover the different necessary competences to study parasitology: 1) theoretical with engaging e-learning units, 2) a virtual laboratory, 3) microscopy and 4) case studies. More information about the DMU e-Parasitology ${ }^{\circledR}$ package has been previously described by our team $[6,7]$. 
Table 1. Theoretical content. Each session covered basic life-cycle, pathogenesis, detection, treatment and prevention of the parasites studied. A screenshot of the different DMU e-Parasitology ${ }^{\circledR}$ theoretical units used is/are provided for each session respectively.

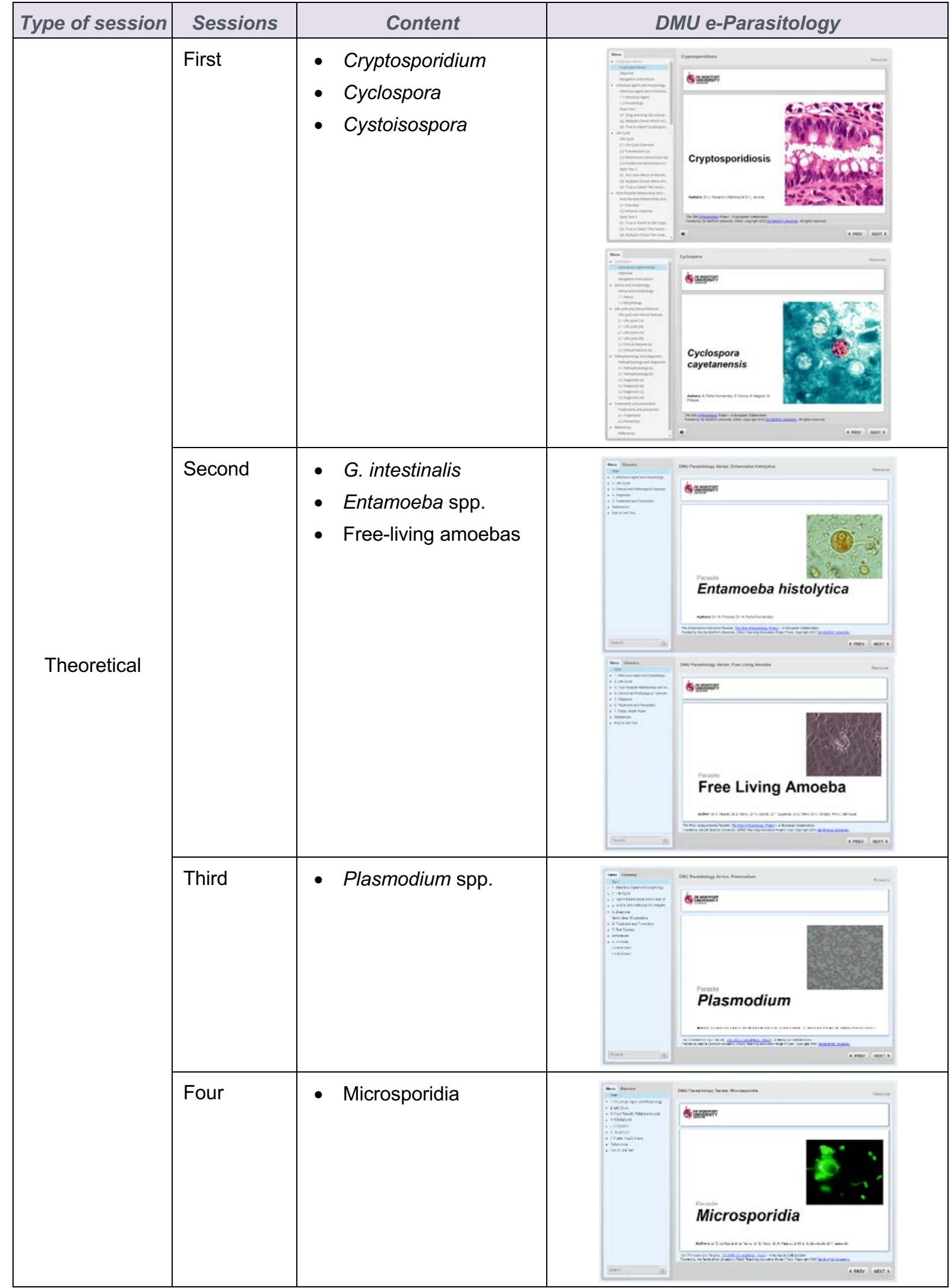

(Images courtesy of DMU; Peña-Fernández A. [5]). 
As practical content, the following one-hour sessions were delivered: biological safety cabinets, molecular techniques, coprological techniques in laboratory, cell culture, and common staining techniques, as indicated in Table 2. Finally, and in order to apply the knowledge learnt during the short course, volunteer UniMak students attended a final session in which they were asked to resolve the virtual clinical case studies available, specifically designed to enhance critical thinking and self-learning.

Table 2. Practical content. Each session covered how to perform the different techniques and/or use the equipment indicated, which was taught by using the different DMU e-Parasitology ${ }^{\circledR}$ virtual laboratory units indicated, which present different descriptive mini-videos.

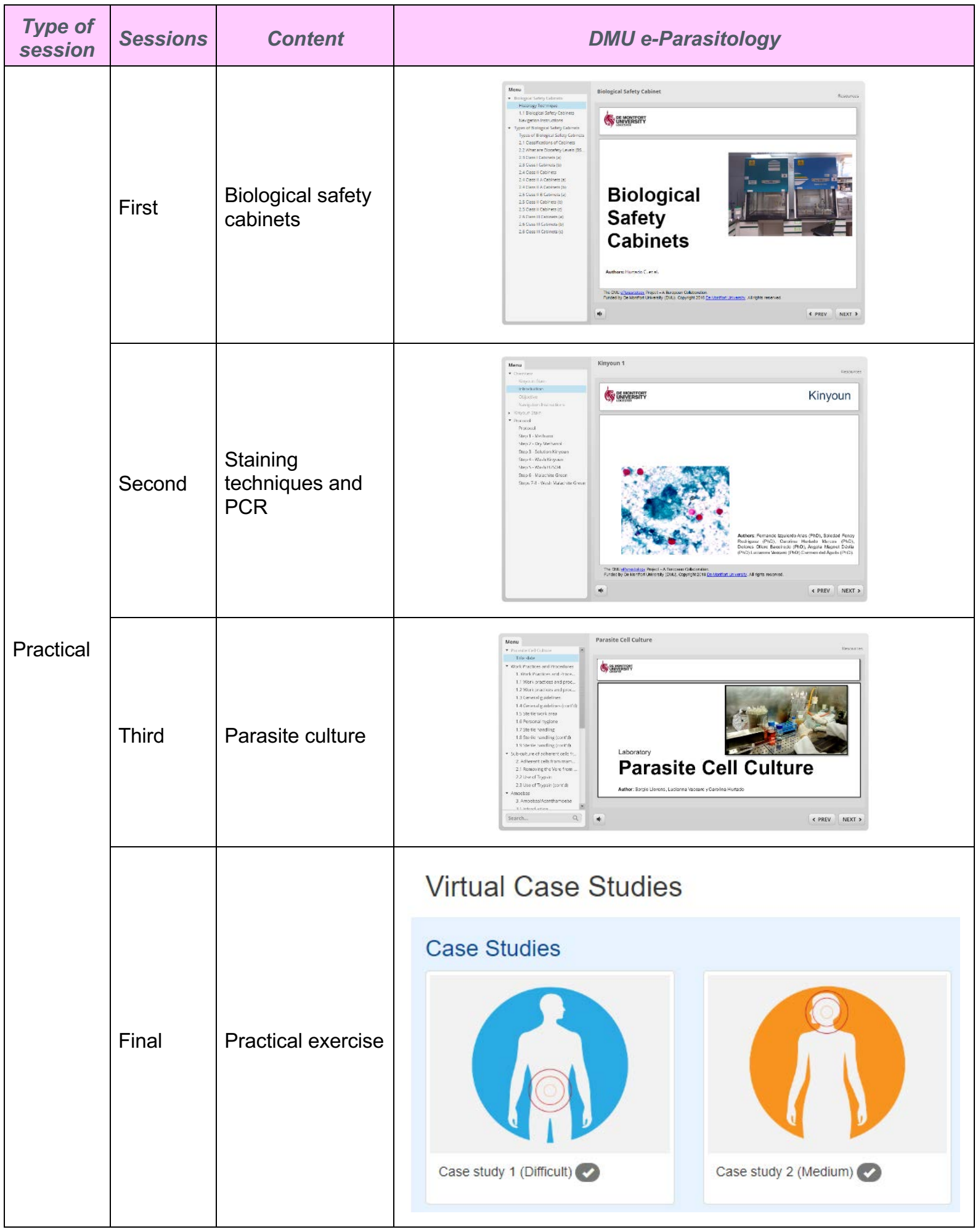

(Images courtesy of DMU; Peña-Fernández A. [5]). 


\subsection{Phase 12: introducing parasitology research.}

Two UniMak academics were hired to help initiate and implement this phase of the project, which consisted in exploring the presence and distribution of different emerging and opportunistic human pathogens in the district of Bombali, one of the biggest in Sierra Leone and location of UniMak. These academics were appropriately trained by the DMU's researcher and helped him in the collection and initial process of a comprehensive number of animal faecal and environmental samples around this Sierra Leonean district. The active involvement of UniMak academics in our project was critical as they shared their culturally sensitive public health expertise to broker parasitology research in communities and be able to collect sensitive samples from different locations. The project would not have been possible without this cultural sensitivity and the way in which they explained the importance of parasitology research in a country where communities are often still traumatised by experiences during the Ebola epidemic. The presence of coccidian parasites, Cryptosporidium spp. and Cyclospora spp., was initially microscopically studied in some of the collected samples, which in turn allowed UniMak's academics to learn these techniques with the aim of developing new practical's in parasitology at their university and enhance their university's research capabilities in parasitology.

\section{RESULTS AND DISCUSSION}

Students that attended the short parasitology course provided and completed the practical exercise indicated in Table $2(n=31)$ and provided comprehensive feedback, which is being comprehensively analysed. Although preliminary, a first review of the feedback provided illustrated that a high percentage of participants enjoyed the short course and would recommend a more comprehensive study of this science in their programmes. These preliminary results are in agreement with previous feedback collected by our research group from postgraduate healthcare students at DMU that have tested the virtual medical parasitology case studies, results that have been described in Peña-Fernández et al. $(2018 a, b[8,9])$.

Our preliminary results have also shown that the DMU e-Parasitology ${ }^{\circledR}$ package could facilitate the introduction of basic medical parasitology in universities in low-income countries with very little teaching and resources currently available for appropriate training. Thus, following the two weeks of training, UniMak's academics performed different curriculum modifications to the undergraduate programme 'Public Health: Medical Laboratory Sciences', which includes the introduction of new practicals in parasitology, such as, a new voluntary practical to detect coccidian parasites in the level 4 module of 'Medical Bacteriology and Parasitology'. To deliver this practical, UniMak academics used the DMU eParasitology ${ }^{\circledR}$ resources, specifically the Kinyoun stain e-learning unit. Eighteen students voluntarily attended this practical recently; the team is collecting feedback from these students to complete introduction of this new parasitology practical in the next academic year.

\section{CONCLUSIONS}

Culture and tradition are not something normally considered when planning biomedical research in African countries, but has been critical to be able to implement this project, teach and collect relevant samples to determine the presence and distribution of these emerging human parasites in the near future. We could not have done this project without the expertise of the Sierra Leonean academics who brokered relationships to allow us to collect our samples and on whose expertise we could built on to teach.

Although our project is at a preliminary stage, it has been shown to be effective in promoting the introduction and completing the first steps for the establishment of medical parasitology at UniMak. The methods and resources described here could be viewed as a case-study for introducing parasitology in other universities in low-income countries to improve public health understanding of emerging and opportunistic parasitic diseases.

\section{ACKNOWLEDGEMENTS}

The authors would like to express their appreciation to University of Makeni and Sierra Leonean population for allowing us to perform this project. The authors would also like to thank the DMU's Quality Research Global Challenges Research Fund (QR GCRF) 2018-19, for funding this project, to Dr. PeñaFernández. Additionally, the authors would like to thank Project FERTILIX 2019 (IMIDRA) for their contribution to this project. 


\section{REFERENCES}

[1] DMU e-Parasitology: Kinyoun stain unit. Available at:

http://parasitology.dmu.ac.uk/learn/lab/Kinyoun/story_html5.html [accessed 25/09/2019]

[2] Keita M., Diallo B., Mesfin S., Marega A., Nebie KY., Magassouba N., Barry A., Coulibaly S., Barry B., Baldé MO., Pallawo R., Sow S., Bah AO., Balde MS., Van Gucht S., Kondé MK., Diallo AB., Djingarey MH., Fall IS., Formenty P., Glynn JR., Subissi L1. Subsequent mortality in survivors of Ebola virus disease in Guinea: a nationwide retrospective cohort study. Lancet Infect Dis 2019. pii: S1473-3099(19)30313-5. doi: 10.1016/S1473-3099(19)30313-5.

[3] Fausther-Bovendo $\mathrm{H}$. and Kobinger $\mathrm{G}$. Increased mortality in survivors of Ebola virus disease. Lancet Infect Dis. 2019 Sep 4. pii: S1473-3099(19)30429-3. doi: 10.1016/S1473-3099(19)30429-3.

[4] WHO, 2016. Ebola Situation Report - 30 March 2016. Available at: http://apps.who.int/ebola/current-situation/ebola-situation-report-30-march-2016 [accessed 25/09/2019]

[5] Peña-Fernández A. DMU e-Parasitology. Available at: http://parasitology.dmu.ac.uk/ [accessed 25/09/2019]

[6] Peña-Fernández A., Magnet A., Acosta L., Evans MD., Fenoy MS. Developing a digital environment for teaching and learning parasitology. Higher Education Academy STEM conference 2018, Newcastle, UK, 31st Jan - 1st Feb 2018. Oral presentation. Available at: https://www.heacademy.ac.uk/knowledge-hub/developing-digital-environment-teaching-andlearning-parasitology-stem-conference [accessed 25/09/2019]

[7] Peña-Fernández A., Evans MD., Hurtado C., Acosta L., Izquierdo F., Magnet A., Peña MA., Singh N., Fenoy S., Bornay FJ., del Águila C. Blended learning for teaching cell culture as part of DMU e-Parasitology. In: Al futuro con el pasado: X Encuentro de Innovación en Docencia Universitaria. Eds. Del Castillo Fernández H. and Gómez Hernández P. Alcalá de Henares: Servicio de Publicaciones de la Universidad de Alcalá, 2019: pp. 461-477. ISBN: 978-84-17729-88-2. Available at: https://www3.uah.es/ice/ID/publicaciones_id.html [accessed 25/09/2019]

[8] Peña-Fernández A., Magnet A., Peña MA. Focus group to create a virtual case study model unit for the DMU e-Parasitology. EDULEARN18 Proceedings 2018a; pp. 7104-7108. ISBN: 978-8409-02709-5. Available at: https://library.iated.org/view/PENAFERNANDEZ2018FOC [accessed 25/09/2019]

[9] Peña-Fernández A. and Peña MA. Teaching medical parasitology in a new Physician Associate master's programme. ICERI2018 Proceedings 2018b; 5229-5234. ISBN: 978-84-09-05948-5. Available at: https://library.iated.org/view/PENAFERNANDEZ2018TEA2 [accessed 25/09/2019] 